\title{
A Smart Distance Power Electronic Measurement Using Smartphone Applications
}

\author{
Mohannad Jabbar Mnati ${ }^{1,2^{*}}$, Raad Farhood Chisab ${ }^{4}$, Alex Van den Bossche $e^{1,3}$ \\ ${ }^{1}$ Department of Electrical Energy, Systems and Automation, Ghent University, Belgium. \\ ${ }^{2}$ Department of Electronic Technology, Institute of Technology Baghdad, Middle Technical \\ University, Iraq. \\ ${ }^{3}$ Flanders Make, the Strategic Research Centre for the Manufacturing Industry, B-8500 \\ Kortrijk, Belgium. \\ ${ }^{4}$ Department of Electrical Technology, Technical Institute Kut, Middle Technical University, \\ 10074 Baghdad, Iraq.
}

Tel: +32 / (0) - 488383749 .

E-Mail: mohannad.mnati@ugent.be, alex.vandenbossche@ugent.be, raadfarhood@yahoo.com

*Correspondence: E-mail: mohannad.mnati@ugent.be,m.j.mnati@gmail.com.

\section{Acknowledgements}

The first author thanks the Ministry of Higher Education and Scientific Research/IRAQ and Special Research of Ghent University for their financial support during this work.

\section{Keywords}

«SDPEM » « Smartphone » « Arduino UNO » « Bluetooth » « Voltage measurement circuit »

\begin{abstract}
The objectives of this article were to design a low-cost three-phase AC voltage measurement circuit and new Android smartphone application to monitor the measuring voltage from a safe distance. The smart distance power electronic measurement (SDPEM) system was designed based on an Arduino UNO R3 board used as a microcontroller to read and calculate the RMS values from a three-phase AC voltage measurement circuit (line-to-line or phase voltage of grid). Following this, the microcontroller sends the measuring data by Bluetooth to an Android smartphone application. The Bluetooth shield V2.0 was used as a wireless communication instrument between the SDPEM and the smartphone or tablet application. The smartphone monitoring application was a new application designed by the open-source developed program (MIT App Inventor 2) to monitor the three-phase AC voltage results from a safe distance. The safe distance depends on the type of Bluetooth device used. The main advantages of the SDPEM system are low cost and safety.
\end{abstract}

\section{Introduction}

Over the past few years, mobile devices have evolved very quickly and have become more than just a means of communication between individuals due to the different technologies that these devices now have that enable them to communicate with surrounding devices. Some of these technologies are present in mobile devices such as Wi-Fi, Bluetooth and Infrared. Different types of communication technologies were integrated with the smart monitoring of measurements and control devices [1]-[7]. In addition, many types of control systems based on Arduino are presented in [4], [5], [8]-[14]. 
Measuring and protection circuits are one of the primary aspects of all power electronic systems. In this paper, a new design of a three-phase AC voltage monitoring system is presented as shown in Fig. 1. This system is called a 'Smart Distance Power Electronic Measurement' (SDPEM) system and can be divided into three parts: measurement circuit, wireless communication system and Android smartphone monitoring application. The first part, the measuring circuit, can be subdivided into two parts: 1) A differential voltage reduction circuit [15], [16] used as an operational amplifier to step-down the grid voltage into an $\mathrm{AC}$ voltage of less than 5 volts since the microcontroller cannot read a voltage larger than 5 volts; 2) An Arduino UNO R3[17], which functions as a microcontroller used to measure the three-phase voltage from the step-down circuits and then calculate the RMS of the voltages before sending the data to an Android smartphone instrument. The second part is a Bluetooth shield V2 which functions as a wireless communication system between the control circuit and the smartphone [18] while the last part is the Android monitoring application, which, in this paper, is a new application software made by using an MIT App Inventor 2 platform to monitor the received data from the control system [19]-[23]. This platform is an open-source, block-based environment application released by Google for creating Android smartphone and tablet applications. The main advantages here are low circuit cost and increased safety for supervision.

The paper is organised as follows: section two presents the system architecture of the SDPEM; section three presents a description of the hardware and software architecture of the SDPEM and section four presents the results and discussion on the practical system and smartphone application. Finally, section five presents the conclusion of the paper.

\section{System Architecture}

The block diagram of the smart distance power electronic measurement system (SDPEM) is shown in Fig. 1. The SDPEM is designed to ensure easy interaction between human and machine. The system can be divided into two parts: a three-phase voltage measuring system and a monitoring system. The Arduino UNO R3 works as a controller between the three-phase voltage measuring circuit and Bluetooth, as a wireless communication system, constitutes the three-phase voltage data access system. The Arduino UNO controls the Bluetooth before receiving the data to be displayed on a smartphone in real time from a safe distance.

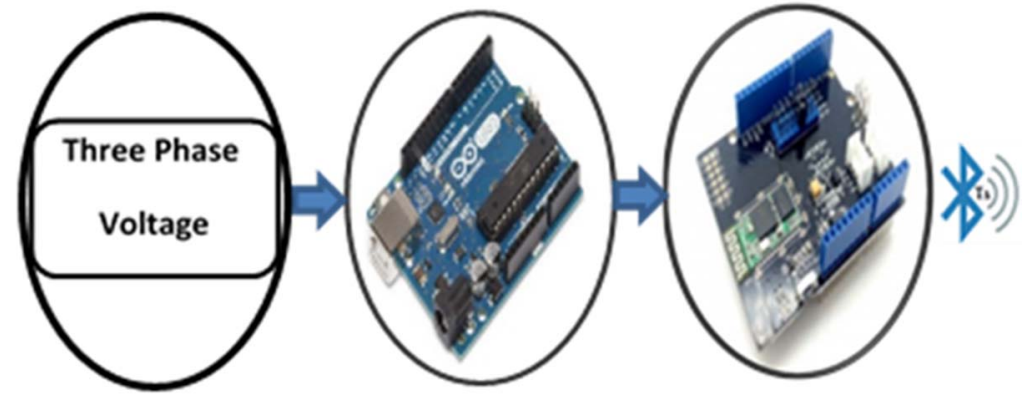

(a)

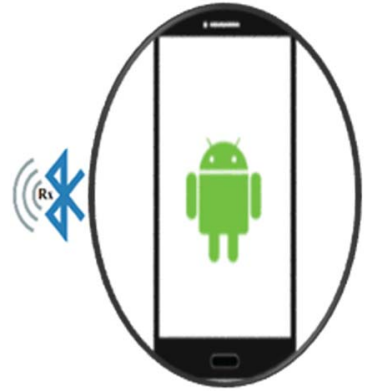

(b)

Fig. 1: SDPEM system description: (a) Control circuit (measuring and wireless communication circuit); (b) Monitoring application 


\subsection{Control Model}

The control system can be divided into three parts:

1. A step-down voltage circuit: this circuit was connected between the three-phase high voltage system and the microcontroller.

2. Arduino Uno R3: the Arduino works as a microcontroller to measure the voltage and calculate the RMS values of three-phase voltage before sending the measuring data via a wireless communication system.

3. Bluetooth: this functions as a wireless communication system between the SDPEM system and the Android smartphone application (human).

\subsection{Smartphone Application}

This is a new application software designed to monitor the measuring data from the three-phase system.

\section{Hardware and Software Architecture}

In this part of the paper we will discuss the two important parts of the SDPEM system, which are the control system and the monitoring system.

\subsection{Hardware Architecture (Control Model)}

The hardware of the SDPEM system model can be subdivided into three parts: the AC measurement circuit; the Arduino UNO R3 and the Bluetooth shield V2. The first part provides three-phase isolated circuits for measuring the voltage of the three-phase system. The second part functions as a microcontroller to read and calculate the RMS values of the voltages before sending the data to monitors via Bluetooth. The last part, the Bluetooth shield V2, functions as a wireless communication system between the three-phase system and the smartphone monitoring system.

\subsubsection{AC voltage measurement circuit}

There are two methods to step down $\mathrm{AC}$ voltage to a low alternating $\mathrm{AC}$ voltage, which should not have a peak value of greater than $5 \mathrm{~V}$. These two methods are:

1.Step-down potential by using a transformer

2.Step-down potential by using a difference amplifier

Method two (difference amplifier) is shown in Fig. 2 and was used as the measurement circuit stepdown voltage for this paper. This circuit is designed to step down voltage to less than $5 \mathrm{~V}$ and measures the voltage less than $400 \mathrm{~V}$ A.C. It also removes the common mode voltage. The capacitors $\mathrm{C} 1$ and $\mathrm{C} 2$ compensate for the parasitic capacitance of the high voltage resistances. 


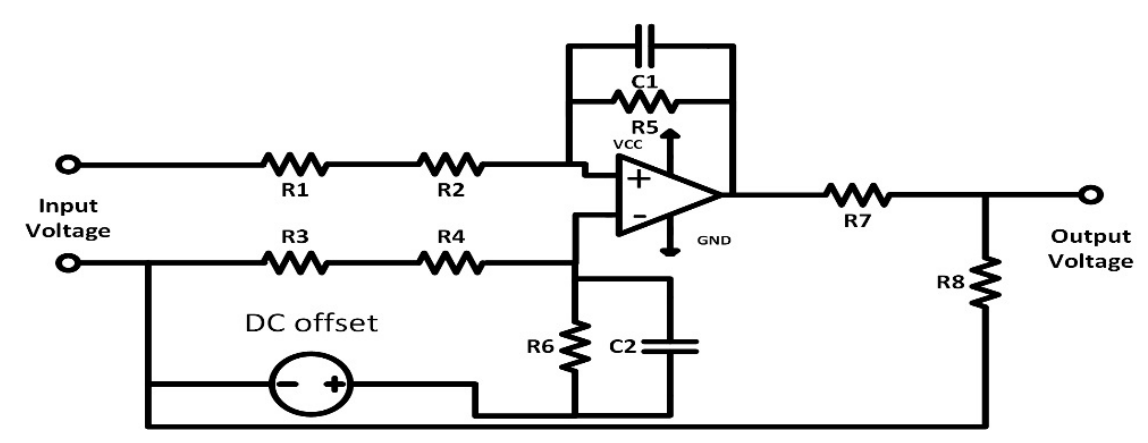

Fig. 2: AC voltage measurement circuit

\subsubsection{Arduino Uno R3 controller}

The Arduino Uno R3 board, which is shown in Fig. 3a, functions as a microcontroller for the SDPEM circuit. The Arduino UNO is an ATmega328 microcontroller that has six analogue input pins (A0-A5), 14 digital input/output pins (six of these 14 can be used as PWM output pins) with 16 MHZ as Clock Speed. The main properties of the Arduino Uno R3 board are shown in Table I.

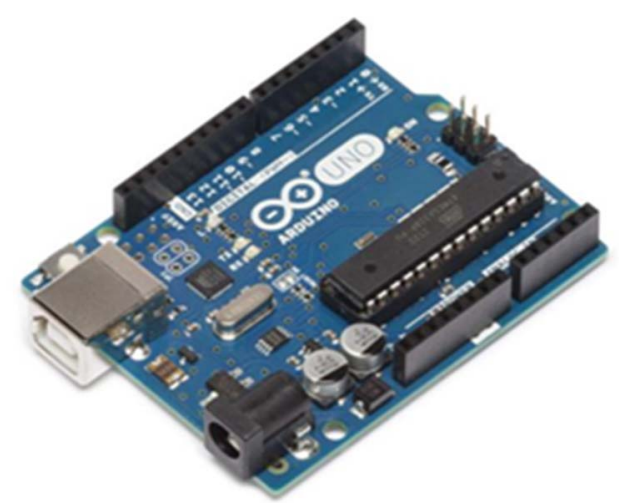

(a)

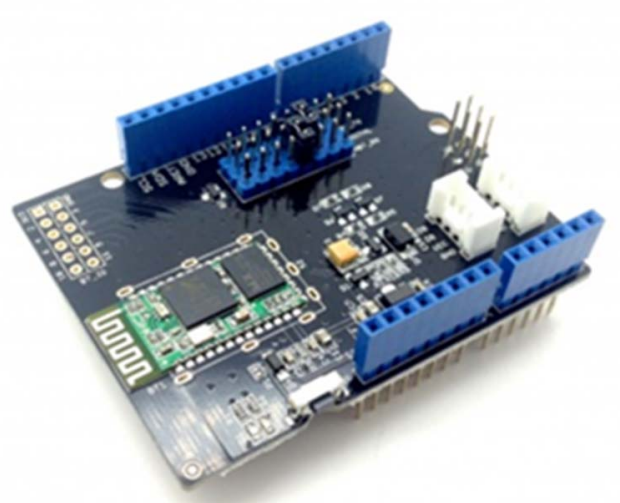

(b)

Fig. 3: Control circuit: a) Arduino UNO R3 Board, b) The Bluetooth Shield V2.0

Table I: Arduino UNO R3 Properties

\begin{tabular}{|l|l|}
\hline Microcontroller & ATmega328 \\
\hline Input Voltage & $7-12 \mathrm{~V}$ \\
\hline Operating Voltage & $5 \mathrm{~V}$ \\
\hline No. of Digital I/O Pins & 14 (of which six provide PWM outputs) \\
\hline No. of Analogue Input Pins & 6 \\
\hline DC Current per I/O Pin & $40 \mathrm{~mA}$ \\
\hline Flash Memory & $0.5 \mathrm{~KB}, 2 \mathrm{~KB}$ of SRAM and 1KB of E2PROM \\
\hline
\end{tabular}




\subsubsection{The Bluetooth Shield V2.0}

For this paper, the Bluetooth Shield V2.0 module (Fig. 3b) is used as a wireless serial data communication system between the Android Application device and the Arduino UNO R3 board. The PCB Antenna of this Bluetooth is on board and the main properties of the Bluetooth Shield V2.0 board are shown in Table II.

Table II: The Bluetooth Shield V2.0 Properties

\begin{tabular}{|l|l|}
\hline Input Voltage & $3.3 \mathrm{~V}$ \\
\hline Communication Distance & Up to 10 metres \\
\hline Baud Rate (Default 9600) & $19200,38400,57600,115200,230400,460800$ \\
\hline PINCODE: & "1234" or "0000" \\
\hline Data, Stop bit: 1, Parity & 1Byte, I Bit, No parity \\
\hline
\end{tabular}

\subsection{Software Architecture}

The software of the SDPEM system is divided into two programs: a control system program and a monitoring application program.

\subsubsection{The control program of the SDPEM system}

The first program, the control program or the Arduino UNO R3 program, is used to measure and calculate the RMS values of the three-phase voltage from the step-down circuit before sending the data via Bluetooth to the monitoring application. The Arduino software (IDE) is an open source platform and is easy to use for writing code. Fig. 4 shows the main screen of the Arduino software (IDE) with the main program of the control system. A flow chart of the control program is presented in Fig. 5a.

\subsubsection{The monitoring program of the SDPEM system}

The second program is a monitoring program for smartphone applications. This program was designed by an MIT App Inventor 2. The MIT app Inventor 2 main screen, shown in Fig. 6, is an open-source online software released by Google for creating smartphone Android applications. This app is an environment-based block for creating Android applications. An MIT App Inventor project consists of a combination of ingredients (e.g. texts, images and buttons) and a program that determines their behaviours. Fig. $5 \mathrm{~b}$ shows the flow chart of the smartphone application program. 


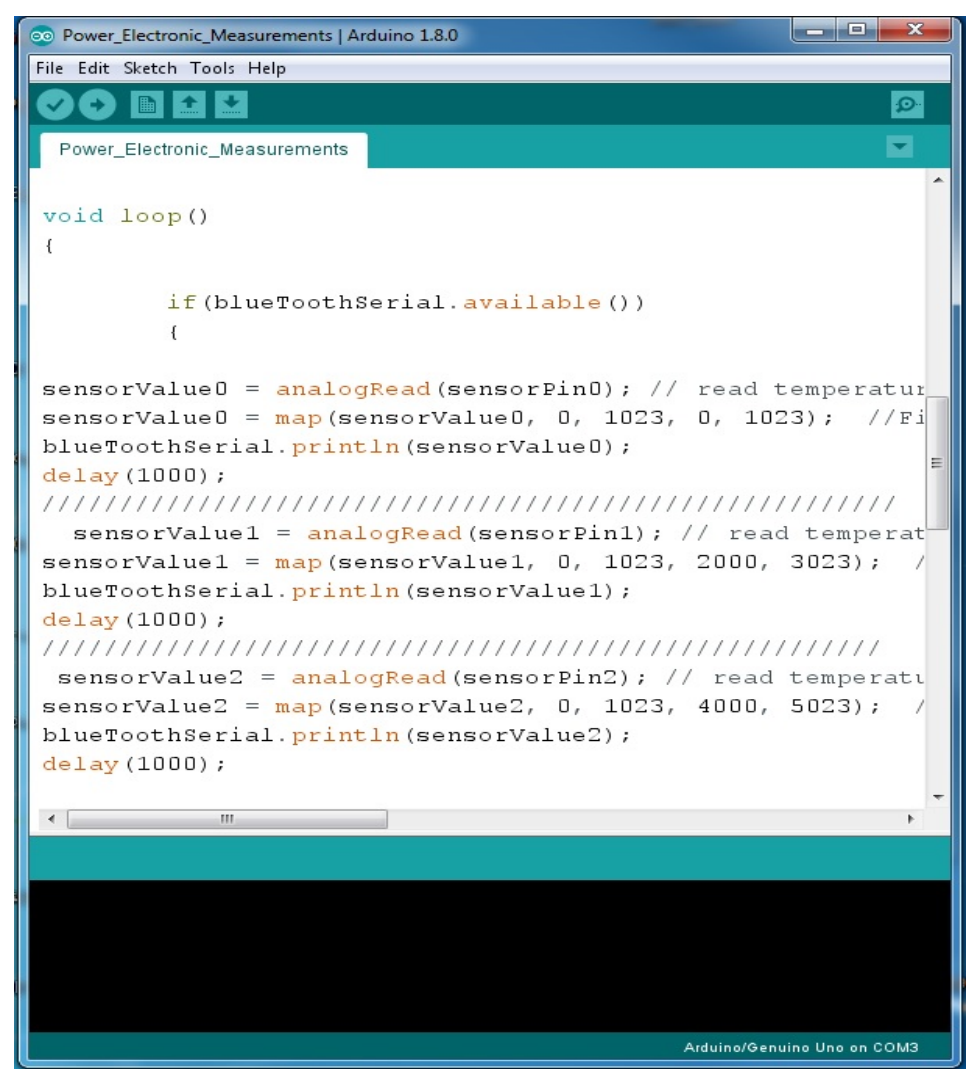

Fig. 4: The main screen of the Arduino program (IDE)

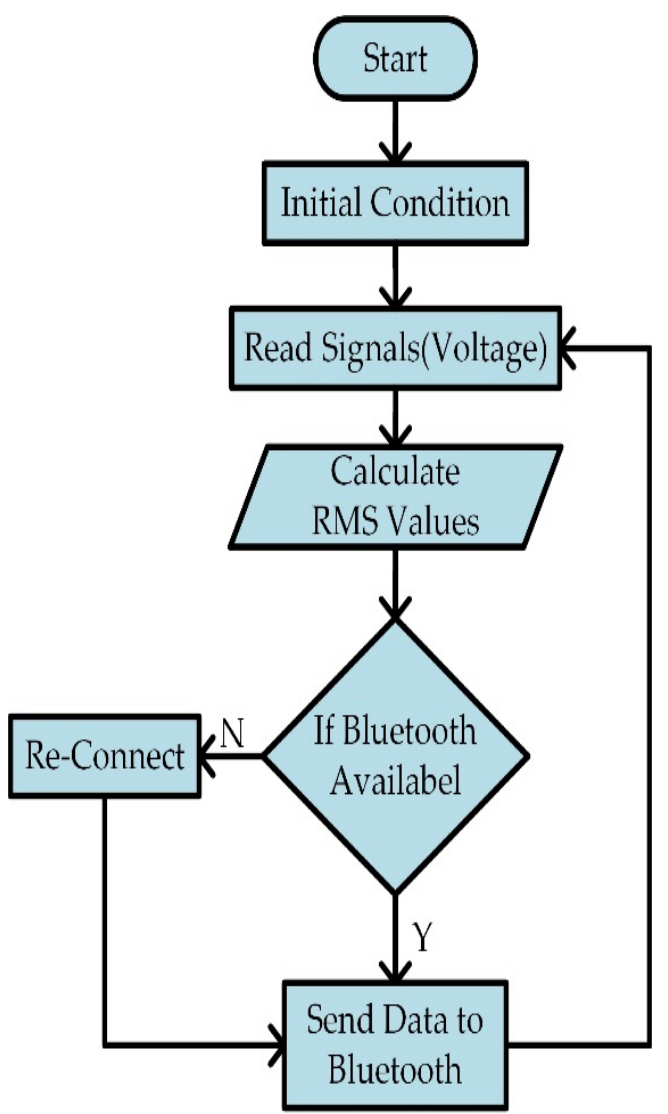

(a)

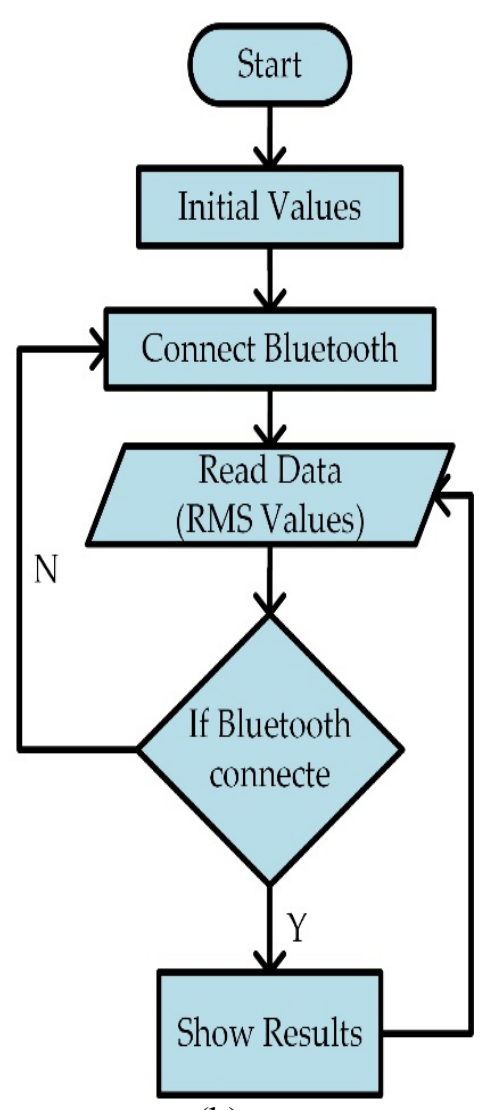

(b)

Fig. 5: Software Flowchart: a) Arduino program flowchart, b) Monitoring application flowchart 


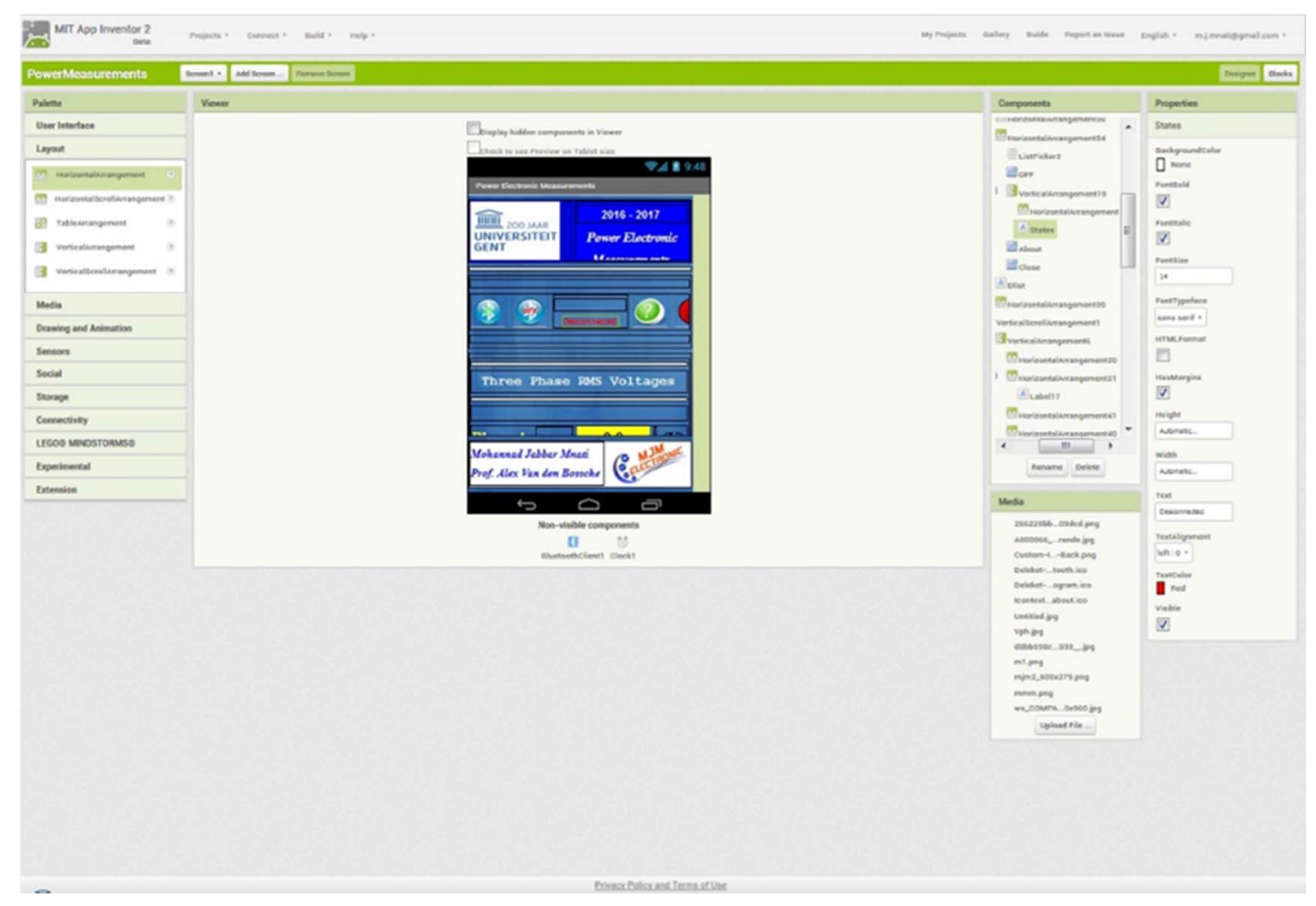

Fig. 6: The main screen of MIT app Inventor 2

\section{Results and Discussion}

In accordance with the single-phase AC measurement circuit shown in Fig. 2, the Matlab simulation of the three-phase step-down voltage circuit is carried out and is shown in Fig. 7. The input and output signals of the three-phase step-down circuit is clearly presented in Fig. 8. Meanwhile, Fig. 8a shows the input and output voltage with $220 \mathrm{~V}$ as a supply input and Fig. $8 \mathrm{~b}$ presents the results with a $400 \mathrm{~V}$ supply input.

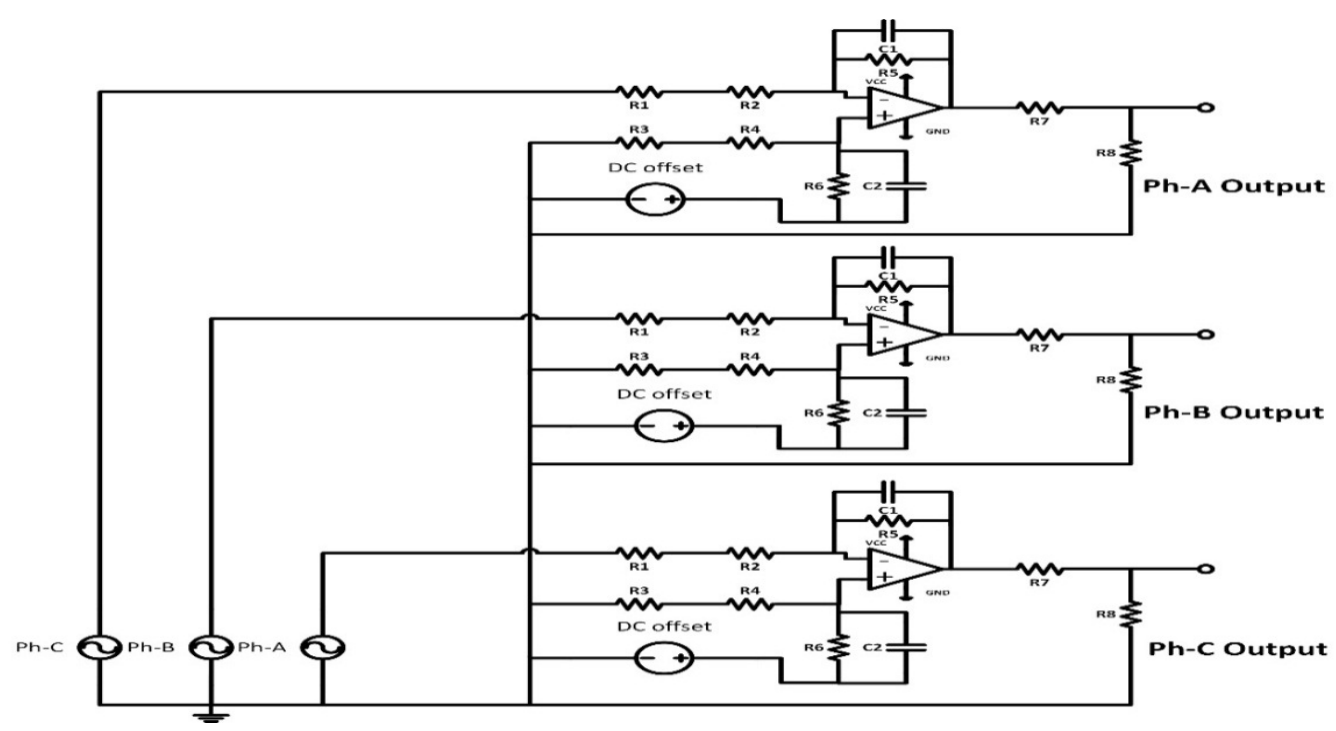

Fig. 7: Three-phase measurement circuit 
The final practical circuit is shown in Fig. 9. Here, the circuit of the three AC step-down voltage is connected to the analogue input ports of the Arduino UNO R3 (A0, A1 and A2). Following this, the Arduino reads all measuring data in a specified time to calculate the RMS values and then sends this data via the Bluetooth shield 2.0 to an Android smartphone or tablet application. The band rate of Bluetooth communication and Arduino UNO R3 is 9600 bits/second.

The Android application of the SDPEM is shown in Fig. 10a as the main screen of the application before Bluetooth connection and Fig. 10b shows it after connection with the measuring data. Meanwhile, Fig. $10 \mathrm{c}$ and Fig. 10d show additional explanation screens displaying information on the conference, circuit and abstract of the paper.

Three phase input voltage $220 \mathrm{~V}, 50 \mathrm{~Hz}$

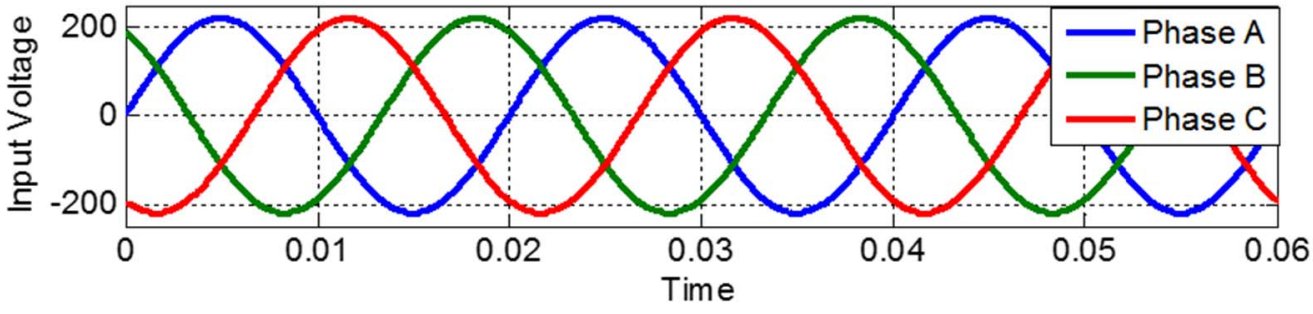

Three phase Output (Input voltage 220V , $50 \mathrm{~Hz}$ )

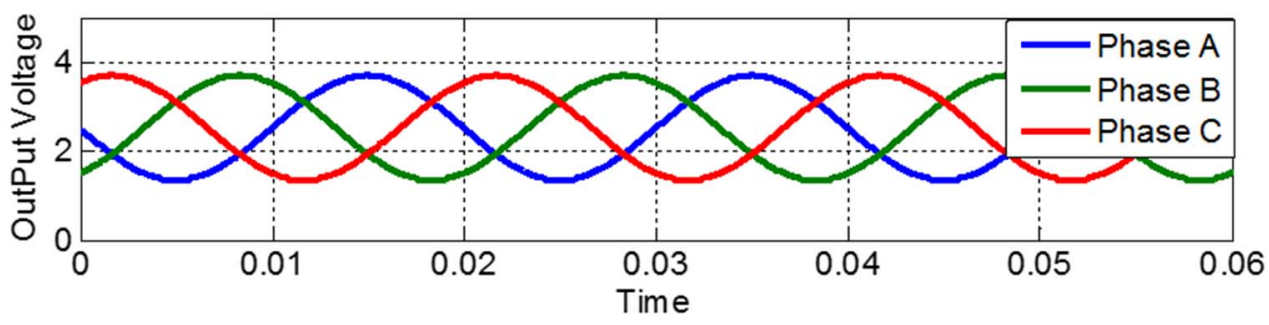

(a)

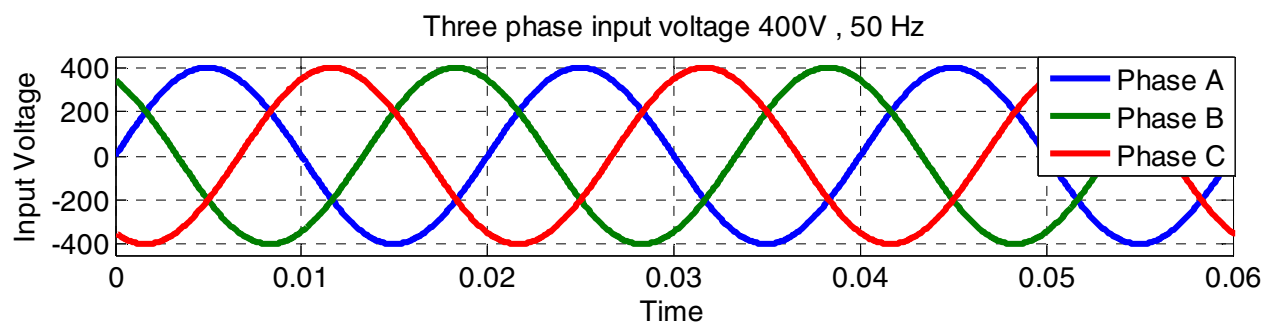

Three phase Output (Input voltage 400V , $50 \mathrm{~Hz}$ )

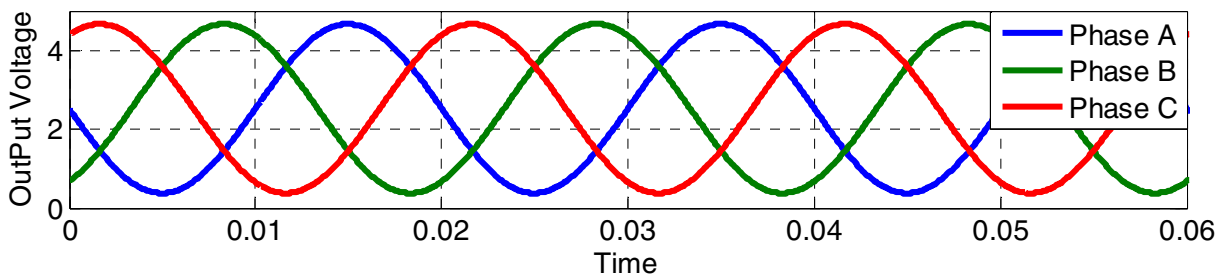

(b)

Fig. 8: Three-phase input and output signals. a) $220 \mathrm{~V}$ and $50 \mathrm{~Hz}$, b) $400 \mathrm{~V}$ and $50 \mathrm{~Hz}$ 


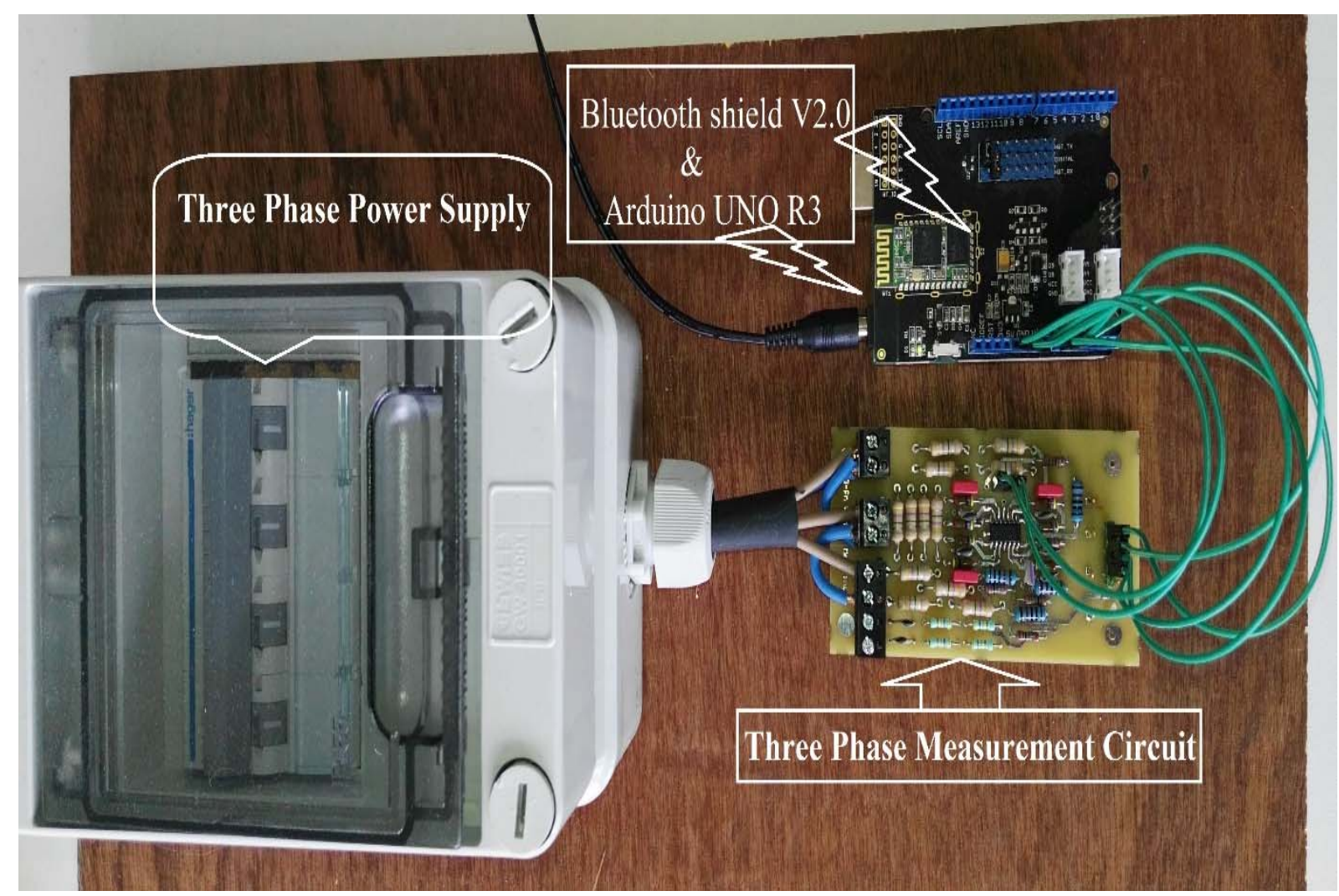

Fig. 9: Practical circuit of the SDPEM system

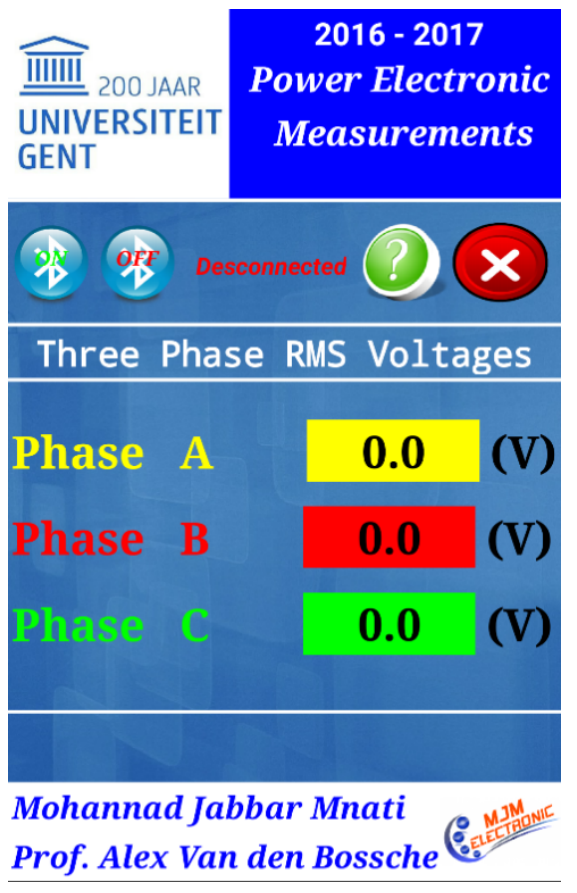

(a)

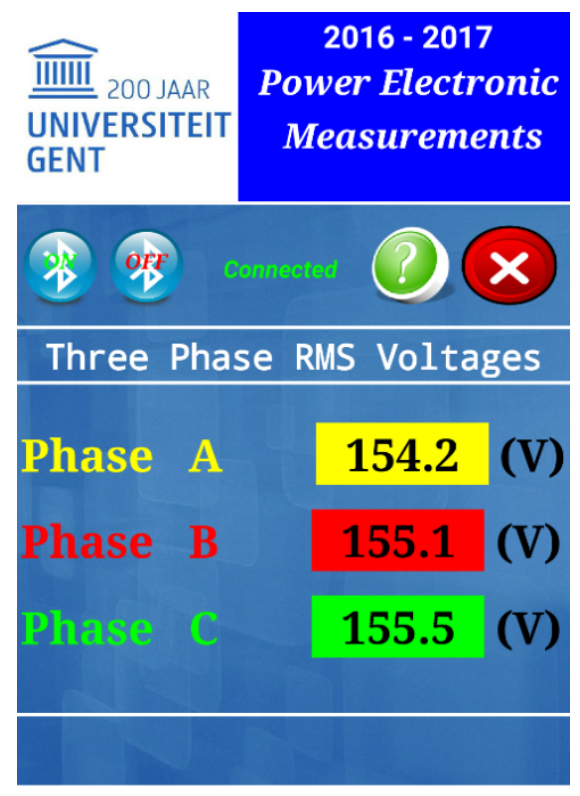

Mohannad Jabbar Mnati

Prof. Alex Van den Bossche 


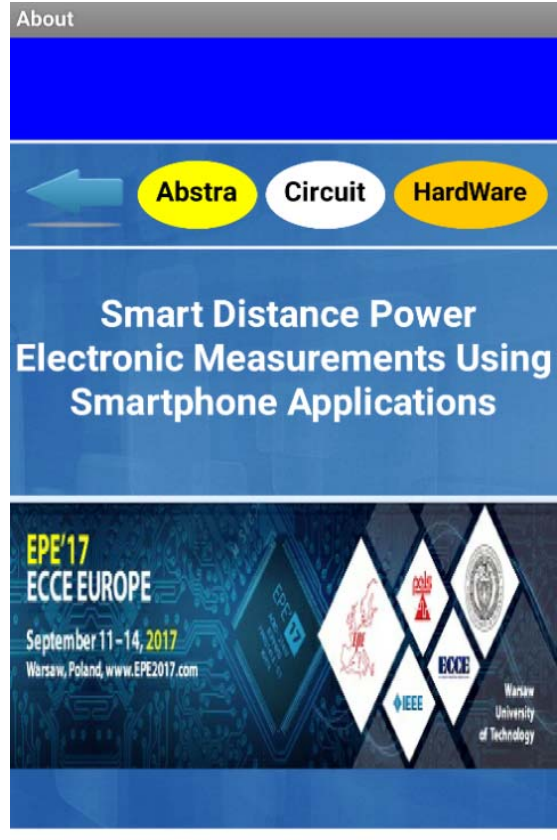

(c)

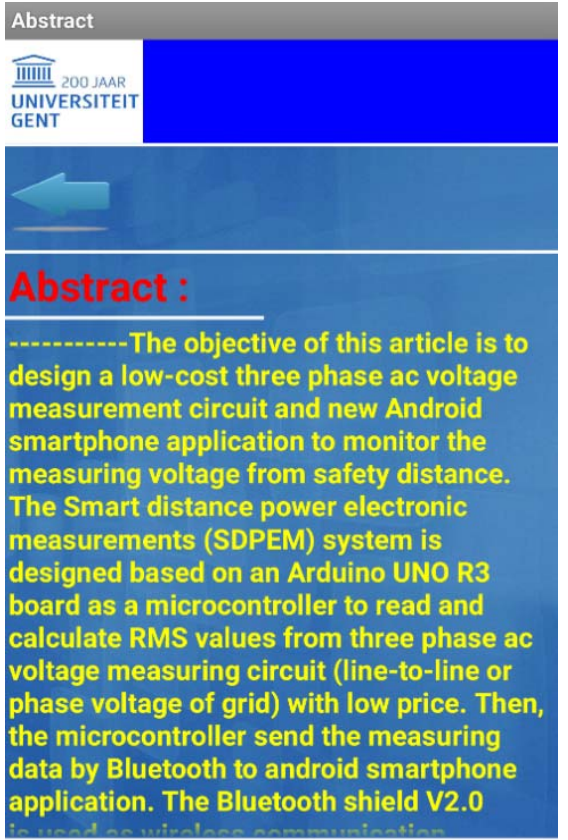

(d)

Fig. 10: Final SDPEM smartphone application. a) main screen before Bluetooth is connected, b) main screen after Bluetooth is connected, c) additional screen (conference information), d) additional screen (paper abstract)

\section{Conclusion}

This paper presented a new Android smartphone or tablet application using the MIT App Inventor 2 platform for monitoring the $\mathrm{AC}$ voltage from a three-phase system. The AC circuit measures the output voltage of a three-phase inverter or grid voltage (voltage measured until 440V AC) and an Arduino Uno R3 functions as a controller to measure and calculate the high voltage signals before sending the data via Bluetooth shield 2.0 to a smartphone or tablet application. This method is accurate and involved low costs in addition to being safer since any individual monitoring the process does not need to be near the electricity board in order to read the three-phase voltages.

\section{References}

[1] V. Varshney, R. K. Goel, and M. A. Qadeer, "Indoor positioning system using Wi-Fi \&amp; Bluetooth Low Energy technology,” 2016 Thirteen. Int. Conf. Wirel. Opt. Commun. Networks, pp. 1-6, 2016.

[2] R. Joaquinito and H. Sarmento, "A Wireless Biosignal Measurement System using a SoC FPGA and Bluetooth Low Energy,” pp. 36-40, 2016.

[3] Mohannad Jabbar Mnati, Alex Van den Bossche, and Raad Farhood Chisab, "A Smart Voltage and Current Monitoring System for Three Phase Inverters Using an Android Smartphone Application," Sensors, vol. 17, no. 4, p. 872, 2017.

[4] S. Kumar and S. S. Solanki, "Voice and touch control home automation," 2016 3rd Int. Conf. Recent Adv. 
Inf. Technol. RAIT 2016, pp. 495-498, 2016.

[5] A. H. Sabani and R. Jailani, “Android based control and monitoring system for leg orthosis,” Proc. - 2015 IEEE 11th Int. Colloq. Signal Process. Its Appl. CSPA 2015, pp. 40-45, 2015.

[6] Ó. Blanco-Novoa, T. Fernández-Caramés, P. Fraga-Lamas, and L. Castedo, “An Electricity Price-Aware Open-Source Smart Socket for the Internet of Energy,” Sensors, vol. 17, no. 3, p. 643, 2017.

[7] E. Bear, T. Maxwell, T. Anglea, D. Raval, I. Buckley, and Y. Wang, "An undergraduate research platform for cooperative control and swarm robotics," 2016 IEEE 11th Conf. Ind. Electron. Appl., vol. 70, pp. 1876-1879, 2016.

[8] L. Müller, M. Mohammed, and J. W. Kimball, "Using the Arduino Uno to teach digital control of power electronics," 2015 IEEE 16th Work. Control Model. Power Electron. COMPEL 2015, 2015.

[9] Y. Wang and Z. Chi, "System of Wireless Temperature and Humidity Monitoring Based on Arduino Uno Platform," 2016 Sixth Int. Conf. Instrum. Meas. Comput. Commun. Control, pp. 770-773, 2016.

[10] H. S. Ahmed and A. A. Ali, "Smart Intensive Care Unit Desgin Based on Wireless Sensor Network and Internet of Things," 2016.

[11] O. E. Departement, "PID Control of a DC Motor Using Labview Interface for Embedded Platforms," pp. $5-8,2016$.

[12] R. Bhadoriya, M. K. Chattopadhyay, and P. W. Dandekar, "Low cost IoT for laboratory environment," 2016 Symp. Colossal Data Anal. Networking, CDAN 2016, pp. 4-7, 2016.

[13] P. N. Patil, M. A. Khandekar, and S. N. Patil, "Automatic dual-axis solar tracking system for parabolic dish," Proceeding IEEE - 2nd Int. Conf. Adv. Electr. Electron. Information, Commun. Bio-Informatics, IEEE - AEEICB 2016, pp. 699-703, 2016.

[14] H. Kovacevic and Z. Stojanovic, "Buck converter controlled by Arduino Uno," 2016 39th Int. Conv. Inf. Commun. Technol. Electron. Microelectron. MIPRO 2016 - Proc., pp. 1638-1642, 2016.

[15] M. Kampik, H. Laiz, and M. Klonz, "2000 - Comparison of three accurate methods to measure ac voltage at low frequency," IEEE Trans. Instrum. Meas., vol. 49, no. 2, pp. 429-433, 2000.

[16] R. W. Fransiska, E. M. P. Septia, W. K. Vessabhu, W. Frans, W. Abednego, and Hendro, "Electrical power measurement using Arduino Uno microcontroller and LabVIEW," Proc. 2013 3rd Int. Conf. Instrumentation, Commun. Inf. Technol., Biomed. Eng. Sci. Technol. Improv. Heal. Safety, Environ., ICICI-BME 2013, pp. 226-229, 2013.

[17] Arduino UNO R3. Available online: https://www.arduino.cc/en/main/arduinoBoardUno.

[18] Bluetooth Shield V2.0. Available online: http://wiki.seeedstudio.com/wiki/Bluetooth_Shield_V2.0.

[19] MIT App Inventor. Available online: http://appinventor.mit.edu/explore/index-2.html.

[20] B. Xie and H. Abelson, "Skill progression in MIT app inventor," Proc. IEEE Symp. Vis. Lang. HumanCentric Comput. VL/HCC, vol. 2016-November, pp. 213-217, 2016.

[21] R. Francese, M. Risi, G. Tortora, and M. Tucci, "Visual Mobile Computing for Mobile End-Users," IEEE Trans. Mob. Comput., vol. 15, no. 4, pp. 1033-1046, 2016.

[22] R. K. Megalingam, S. V. Reddy, G. Sriharsha, P. S. Teja, and K. S. Kumar, "Study and Development of Android Controlled Wireless Pole Climbing Robot," pp. 6-9.

[23] F. Turbak, D. Wolber, and P. Medlock-Walton, “The design of naming features in App Inventor 2," Proc. IEEE Symp. Vis. Lang. Human-Centric Comput. VL/HCC, pp. 129-132, 2014. 